\title{
Distribution of CXCR2 +1208 T/C gene polymorphisms in relation to opportunistic infections among HIV-infected patients in Limpopo Province, South Africa
}

\author{
A. Samie ${ }^{1}$, G.A. Dzhivhuho ${ }^{2}$ and T.C. Nangammbi ${ }^{2}$ \\ ${ }^{1}$ Molecular Parasitology and Opportunistic Infections Program, \\ Department of Microbiology, University of Venda, Thohoyandou, South Africa \\ ${ }^{2}$ Department of Nature Conservation, Faculty of Science, \\ Tshwane University of Technology, Pretoria, South Africa \\ Corresponding author: A. Samie \\ E-mail: samie.amidou@univen.ac.za
}

Genet. Mol. Res. 13 (3): 7470-7479 (2014)

Received July 24, 2013

Accepted January 16, 2014

Published September 12, 2014

DOI http://dx.doi.org/10.4238/2014.September.12.13

\begin{abstract}
Interleukin 8 (IL-8) is a chemokine produced by macrophages and other cell types, including epithelial cells, and its receptor is CXCR2. IL-8 plays an important role in the initiation and amplification of inflammatory diseases, including opportunistic infections. With the advent of human immunodeficiency virus (HIV) and acquired immunodeficiency syndrome, opportunistic infections have become major health concerns. However, the role of host genetics on the occurrence of these infections has not been clearly defined. In this study, genomic DNA was extracted from 185 HIVinfected individuals in the Limpopo Province, South Africa. Allelespecific polymerase chain reaction was used to genotype the CXCR2 +1208 T/C gene. Genotypes CC, TT, and TC were associated with chest pains, frequent headaches, loss of weight, diarrhea, and loss of appetite among HIV patients. A significant association between the CC
\end{abstract}


genotype and chest pains was found $(\mathrm{P}=0.035)$. The $\mathrm{TC}$ genotype was associated with loss of appetite $(\mathrm{P}=0.044)$ and chest pains $(\mathrm{P}=0.042)$. A weak association between diarrhea and the TT genotype was found $(\mathrm{P}=0.082)$. No association was observed between tuberculosis and the genotypes. Immunological characteristics, such as viral load and CD4 count, were not significantly associated with the genotypes. The results of the present study suggest that carriers of the TC genotype are more susceptible to chest pain, but that this genotype confers a protective effect against loss of appetite. The CC genotype was found to confer protection against chest pain but appeared to increase susceptibility to headaches. Further studies using larger samples are necessary to confirm these results.

Key words: CXCR2 +1208 T/C gene; Polymorphism; HIV; Opportunistic Infections; Host genetics; Limpopo Province

\section{INTRODUCTION}

Chemokines are low-molecular weight proteins characterized by their ability to promote the directed chemotaxis of leukocytes. Of the different subclasses of chemokines, the CXC family of chemokines are particularly important in the initiation and amplification of inflammatory diseases (Chapman et al., 2009) such as tuberculosis (TB) (Otsuka et al., 2005), diarrhea (Jiang et al., 2003), chest pain (Stadtmann and Zarbock, 2012), and loss of appetite, which eventually lead to unexplained weight loss. The CXCR2 chemokine receptor is a glycoprotein-coupled receptor found primarily on the surface of leukocytes and binds to interleukin-8 (IL-8) with high affinity.

Inflammatory processes are important components of the defense mechanisms of the body. Despite their normal function, the inflammatory response may result in injury to a variety of organs and tissues if excessive stimulation occurs beyond simply removing the pathogen and healing (Chiche et al., 2001). Opportunistic infections are one of the most common causes of morbidity and mortality among human immunodeficiency virus (HIV) and acquired immunodeficiency syndrome (AIDS) patients. The virus continuously damages the immune system until it can no longer cope with and respond to infections. CD4+ T cells and macrophages are key components of the cellular immune system as the primary targeted cells. The process of inflammation as well as opportunistic infection among patients is regulated by cytokines, which are key protein regulators of the host response to infection (Li et al., 2012).

Various studies have shown that the host cytokine response is genetically determined and polymorphic (Bidwell et al., 1999). There is a growing body of evidence indicating that CXCR2 plays an important role in pulmonary disease (Chapman et al., 2009). Several pharmaceutical companies have identified potent and selective CXCR2 candidates that have now advanced into clinical trials (Chapman et al., 2009). Examining the genetic variation associated with disease will increase the understanding of why some patients die in a short period of time while others remain healthy for longer periods, even if both have the same infection. In this study, we examined genetic polymorphisms in the CXCR2 gene and their association with opportunistic infections among HIV-infected patients. 


\section{MATERIAL AND METHODS}

\section{Recruitment of subjects and sample collection}

The study was approved by the University Health, Safety, and Research Ethics Committee (UNIVEN). The objectives of the study were explained to the patients and written consent forms were obtained before administration of the questionnaires and sample collection. Questionnaires were structured to obtain gender, hospital, treatment, and marital status information. Mouthwash samples were collected from a total of 201 patients randomly selected from 3 different hospitals, including Donald Frazer, Elim, and Tshilidzini, in the Limpopo Province, South Africa. Other samples were collected at the University of Venda. Patient files were also consulted when needed with permission from the hospital review board and the Department of Health, Polokwane. Samples were transported to the Molecular Genetics Laboratory at UNIVEN in a cooler box containing ice. Upon arrival to the laboratory, samples were centrifuged at $2236 \mathrm{~g}$ for $15 \mathrm{~min}$ and the pellet was transferred to a $2-\mathrm{mL}$ microcentrifuge tube and stored in a freezer at $-20^{\circ} \mathrm{C}$ until further use.

\section{DNA extraction and genotyping}

Genomic DNA was extracted from a mouthwash sample and purified using a blood extraction kit (Sigma; St. Louis, MO, USA) as recommended by the manufacturer. Allele-specific polymerase chain reaction (AS-PCR) was performed to detect polymorphisms at positions +1208 of the CXCR 2 gene. As an internal control, $\beta$-globin-specific primers were used. A $20-\mu \mathrm{L}$ PCR mixture was prepared and contained $5 \mu \mathrm{L}$ genomic DNA, $10 \mu \mathrm{L}$ Kappa ready mix Taq polymerase (KAPPA Biotechnologies; Cape Town, South Africa), $0.3 \mu \mathrm{L}$ each specific and common primer, and nuclease-free water. The primers used were CXCR2 $(+1208)$ common (5'-GTCTTGTGAATAAGCTGCTATGA3'), CXCR2 (+1208) C allele (5'-CCATTGTGGTCACAGGAAGC-3'), and CXCR2 $(+1208)$ T allele (5'-CCATTGTGGTCACAGGAAGT-3'), yielding a PCR product of approximately 700-720 base pairs (bp) as described by Snoussi et al. (2010).

The AS-PCR cycling conditions were as follows: pre-denaturation at $96^{\circ} \mathrm{C}$ for 10 min, touch-down procedure of $25 \mathrm{~s}$ at $95^{\circ} \mathrm{C}$, followed by annealing for $45 \mathrm{~s}$ at temperatures decreasing from $55^{\circ} \mathrm{C}$ ( 4 cycles) to $50^{\circ} \mathrm{C}(25$ cycles $)$, and an elongation step at $72^{\circ} \mathrm{C}$ for $40 \mathrm{~s}$; following the reaction, the temperature was held at $4^{\circ} \mathrm{C}$. PCR products of the CXCR2 gene amplification were loaded onto a $1.5 \%$ agarose gel and visualized using a gel documentation system (GBox; Vacutec; Pretoria, South Africa).

\section{Statistical analysis}

All results were analyzed using the Statistical Package for Social Science (SPSS, Inc., 2009; Chicago, IL, USA) version 19 Windows program. The Pearson chi-square test and binary analysis were used to determine the potential association between the genotype distribution and the different demographic and clinical characteristics of patients. 


\section{RESULTS}

\section{Demographic information of participants}

All participants were grouped according to gender, marital status, age group, number of individuals per location, and treatment (Table 1). The population included 124 females $(67.0 \%)$ and 60 males $(32.4 \%)$, with the gender of one sample not identified. Most patients were single $(42.5 \%)$ and most were $25-45$ years old $(55.85 \%)$. A large number of patients were recruited from Donald Frazer $(89 ; 48.1 \%)$, and only a few were from UNIVEN $(15 ; 8.1 \%)$. The most common treatment received by patients was antiretroviral therapy $(97 ; 51.6 \%)$ and prophylaxis $(80 ; 43.5 \%)$; bactrim $(50 ; 26.60 \%)$ was the least common treatment method.

\begin{tabular}{|c|c|}
\hline Characteristic & No. of individuals ( $\%$ of the total sample of 185 ) \\
\hline \multicolumn{2}{|l|}{ Gender } \\
\hline Missing & $1(0.6 \%)$ \\
\hline Male & $60(32.4 \%)$ \\
\hline Female & $124(67.0 \%)$ \\
\hline \multicolumn{2}{|l|}{ Marital status } \\
\hline Divorced & $20(10.81 \%)$ \\
\hline Married & $61(32.97 \%)$ \\
\hline Single & $80(43.24 \%)$ \\
\hline Widow & $24(12.97 \%)$ \\
\hline \multicolumn{2}{|l|}{ Age group } \\
\hline$<25$ years & $12(6.38 \%)$ \\
\hline $25-45$ years & $102(55.85 \%)$ \\
\hline$>45$ years & $71(37.77 \%)$ \\
\hline \multicolumn{2}{|l|}{ Location } \\
\hline Elim & $34(18.4 \%)$ \\
\hline Tshilidzini & $47(25.4 \%)$ \\
\hline Donald Frazer & $89(48.1 \%)$ \\
\hline UNIVEN & $15(8.1 \%)$ \\
\hline \multicolumn{2}{|l|}{ Treatment taken by patients } \\
\hline Prophylaxis & $80(43.55 \%)$ \\
\hline Multi vitamin concentrate (intravenous infusion) (MVI) & $11(5.85 \%)$ \\
\hline Bactrim & $50(26.60 \%)$ \\
\hline Vitamin B complex & $60(31.91 \%)$ \\
\hline Antiretroviral therapy (ART) & $97(51.60 \%)$ \\
\hline General antibiotic usage & $27(14.36 \%)$ \\
\hline
\end{tabular}

\section{PCR amplification to detect and identify genotypes}

Following amplification, band positions were analyzed on the gels according to the expected band sizes. For the CXCR2 T allele, single bands of 700 bp were observed against a $1-\mathrm{kb}$ plus ladder, and dimers were below $50 \mathrm{bp}$. For CXCR2 $\mathrm{C}$ allele detection, double bands of 700-720 bp against a 1-kb plus molecular ladder were observed, and dimers were below 50 bp. Genotypes were determined based on bands that appeared as homozygotes or heterozygotes for each sample (Figure 1).

\section{General distribution of CXCR2 genotypes}

Of the 201 samples collected, only 185 were successfully amplified and consid- 
ered in the final analysis. Of the 3 genotypes, the heterozygous CXCR2 TC genotype was the most predominant in the population studied (79\%) followed by the homozygous CXCR2 CC (15\%) genotype; a few individuals (4\%) expressed the homozygous CXCR TT genotype (Figure 2).

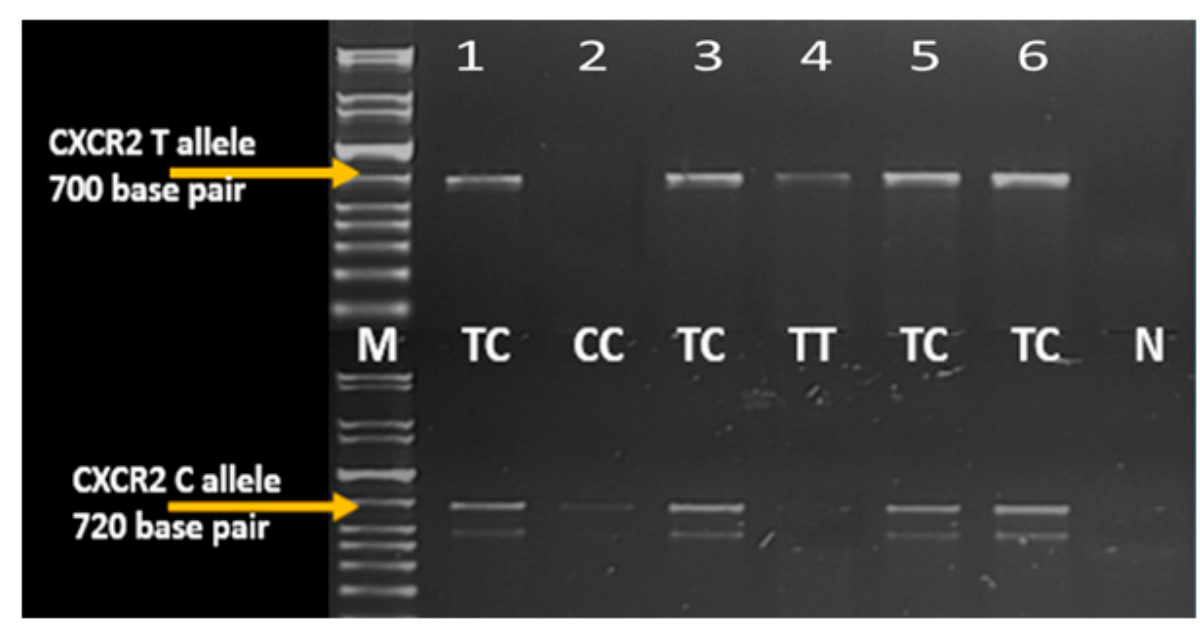

Figure 1. AS-PCR products for the CXCR2 $+1208 \mathrm{C}$ and T allele on $1.5 \%$ agarose gel. Lane $M=1-\mathrm{kb}$ marker, lane $N=$ negative control, and the numbers represent the samples; the genotypes are shown in the middle of the gels as $\mathrm{TC}, \mathrm{CC}$, and TT.

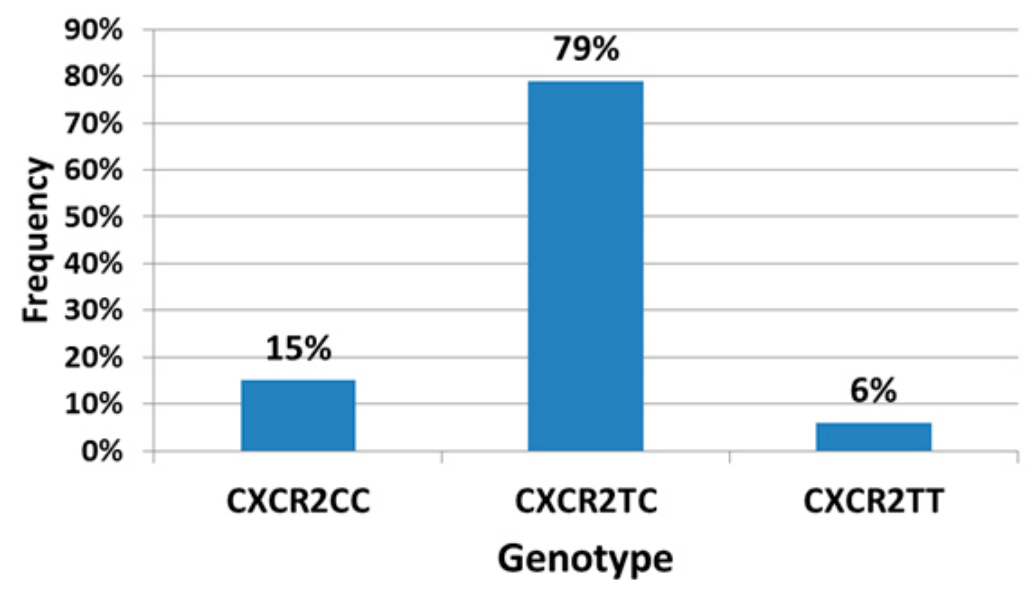

Figure 2. General distribution of the CXCR2 genotypes across the study population.

\section{Correlation between CXCR2 genotype polymorphisms and opportunistic infections}

Opportunistic infections and symptoms reported by the participants included TB, diarrhea, chest pains, and others. Table 2 shows the distribution of different genotypes in relation 
to the occurrence of the different opportunistic infections and symptoms as reported by the patients (or those found in their medical records).

Table 2. Association between the CXCR2 genotype distribution and opportunistic infections.

\begin{tabular}{|c|c|c|c|c|c|c|}
\hline \multirow[t]{2}{*}{ Association } & \multirow[t]{2}{*}{ Genotype } & \multicolumn{2}{|c|}{ Frequency } & \multirow{2}{*}{$\frac{\text { Total }}{\text { Total }(146)}$} & \multirow[t]{2}{*}{$\chi^{2}$} & \multirow[t]{2}{*}{$\mathrm{P}$} \\
\hline & & No (99) & Yes (47) & & & \\
\hline \multirow[t]{4}{*}{ Loss of appetite } & $\mathrm{CC}$ & $13(13.1 \%)$ & $12(25.5 \%)$ & $25(17.1 \%)$ & 3.453 & 0.063 \\
\hline & $\mathrm{TC}$ & $82(82.8 \%)$ & $32(68.1 \%)$ & $114(78.1 \%)$ & 4.048 & $0.044 *$ \\
\hline & TT & $4(4.0 \%)$ & $3(6.4 \%)$ & $7(4.8 \%)$ & 0.383 & 0.536 \\
\hline & & No (86) & Yes (39) & Total (125) & & \\
\hline \multirow[t]{4}{*}{ Frequent headaches } & $\mathrm{CC}$ & $10(11.6 \%)$ & $9(23.1 \%)$ & $19(15.2 \%)$ & 2.729 & 0.099 \\
\hline & $\mathrm{TC}$ & $72(83.7 \%)$ & $28(71.8 \%)$ & $100(80.0 \%)$ & 2.385 & 0.122 \\
\hline & TT & $4(4.7 \%)$ & $2(5.1 \%)$ & $6(4.8 \%)$ & 0.013 & 0.908 \\
\hline & & No (117) & Yes (53) & Total (170) & & \\
\hline \multirow[t]{4}{*}{ Past chest pain } & $\mathrm{CC}$ & $24(20.5 \%)$ & $4(7.5 \%)$ & $28(16.5 \%)$ & 4.457 & $0.035^{*}$ \\
\hline & $\mathrm{TC}$ & $85(72.6 \%)$ & $46(86.8 \%)$ & $131(77.1 \%)$ & 4.127 & $0.042 *$ \\
\hline & TT & $8(6.8 \%)$ & $3(5.7 \%)$ & $11(6.5 \%)$ & 0.084 & 0.773 \\
\hline & & No (138) & Yes (31) & Total (169) & & \\
\hline \multirow[t]{4}{*}{ Current chest pain } & $\mathrm{CC}$ & $26(18.8 \%)$ & $2(6.5 \%)$ & $28(16.6 \%)$ & 2.811 & 0.094 \\
\hline & $\mathrm{TC}$ & $101(73.2 \%)$ & $29(93.5 \%)$ & $130(76.9 \%)$ & 5.911 & $0.015^{*}$ \\
\hline & $\mathrm{TT}$ & $11(8.0 \%)$ & $0(0 \%)$ & $11(6.5 \%)$ & 2.643 & 0.104 \\
\hline & & No (136) & Yes (35) & Total (171) & & \\
\hline \multirow[t]{4}{*}{ Diarrhea } & $\mathrm{CC}$ & $23(16.9 \%)$ & $5(14.3 \%)$ & $28(16.4 \%)$ & 0.140 & 0.708 \\
\hline & $\mathrm{TC}$ & $102(75.0 \%)$ & $30(85.7 \%)$ & $132(77.2 \%)$ & 1.815 & 0.178 \\
\hline & TT & $11(8.1 \%)$ & $0(0 \%)$ & $11(6.4 \%)$ & 3.026 & 0.082 \\
\hline & & No (106) & Yes (22) & Total (128) & & \\
\hline \multirow[t]{3}{*}{ Loss of weight } & $\mathrm{CC}$ & $18(17.0 \%)$ & $6(27.3 \%)$ & $24(18.8 \%)$ & 1.267 & 0.260 \\
\hline & $\mathrm{TC}$ & $86(81.1 \%)$ & $14(63.6 \%)$ & $100(78.1 \%)$ & 3.263 & 0.071 \\
\hline & TT & $2(1.9 \%)$ & $2(9.1 \%)$ & $4(3.1 \%)$ & 3.123 & 0.077 \\
\hline \multirow[t]{4}{*}{ Tuberculosis } & & No (126) & Yes (44) & Total (170) & & \\
\hline & $\mathrm{CC}$ & $21(16.7 \%)$ & $7(15.9 \%)$ & $28(16.5 \%)$ & 0.014 & 0.907 \\
\hline & $\mathrm{TC}$ & $97(77.0 \%)$ & $34(77.3 \%)$ & $131(77.1 \%)$ & 0.002 & 0.969 \\
\hline & TT & $8(6.3 \%)$ & $3(6.8 \%)$ & $11(6.5 \%)$ & 0.012 & 0.913 \\
\hline
\end{tabular}

*P is significant at $\mathrm{P}<0.05$.

Of the 99 patients who did not suffer from loss of appetite, $13 \%$ expressed the $\mathrm{CC}$ genotype; of the 47 patients who suffered from loss of appetite, $25 \%$ expressed the CC genotype, and the difference was nearly significant $\left(\chi^{2}=3.453, \mathrm{P}=0.063\right)$. The TT genotype frequency showed no significant difference between patients with or without loss of appetite. However, the TC genotype was significantly associated with loss of appetite $(\mathrm{P}=0.044)$. A significant association was also observed between the TC genotype and chest pains $(\mathrm{P}=0.042)$, as was the CC genotype $(\mathrm{P}=0.035)$.

\section{CXCR2 genotype polymorphisms in relation to immunological characteristics of participants}

The CD4 count and viral load were reported for some patients in their files. Of the 36 individuals with CD4 counts less than 50 cells $/ \mu \mathrm{L}, 19.4 \%$ carried the CC genotype, $77.8 \%$ carried the TC genotype, and $2.8 \%$ carried the TT genotype; the difference was not significant $(\mathrm{P}=0.396)$. Most participants with a $\mathrm{CD} 4$ count less than 50 cells $/ \mu \mathrm{L}$ carried the TC genotype, but the difference was not significant $(\mathrm{P}=0.954)$. Participants with viral loads $>25$ copies (or undetectable) carried mostly the TC genotype. However, this difference was not statistically significant $(\mathrm{P}=0.526)$ (Table 3$)$. 
Table 3. Association between the CXCR2 genotype distribution and immunological characteristics.

\begin{tabular}{|c|c|c|c|c|c|c|}
\hline \multirow[t]{2}{*}{ Association } & \multirow[t]{2}{*}{ Genotype } & \multicolumn{2}{|c|}{ Frequency } & \multirow{2}{*}{$\begin{array}{c}\text { Total } \\
(160)\end{array}$} & \multirow[t]{2}{*}{$\chi^{2}$} & \multirow[t]{2}{*}{$\mathrm{P}$} \\
\hline & & No (124) & Yes (36) & & & \\
\hline \multirow[t]{4}{*}{$\mathrm{CD} 4<50$ cells $/ \mu \mathrm{L}$} & $\mathrm{CC}$ & $17(13.7 \%)$ & $7(19.4 \%)$ & $24(15.0 \%)$ & 0.720 & 0.396 \\
\hline & $\mathrm{TC}$ & $97(78.2 \%)$ & $28(77.8 \%)$ & $125(78.1 \%)$ & 0.003 & 0.954 \\
\hline & TT & $10(8.1 \%)$ & $1(2.8 \%)$ & $11(6.9 \%)$ & 1.218 & 0.270 \\
\hline & & No $(57)$ & Yes (103) & Total (160) & & \\
\hline \multirow{4}{*}{ CD4 $<200$ cells $/ \mu \mathrm{L}$} & $\mathrm{CC}$ & $6(10.5 \%)$ & $18(17.5 \%)$ & $24(15.0 \%)$ & 1.390 & 0.238 \\
\hline & TC & $46(80.7 \%)$ & $79(76.7 \%)$ & $125(78.1 \%)$ & 0.344 & 0.558 \\
\hline & TT & $5(8.8 \%)$ & $6(5.8 \%)$ & $11(6.9 \%)$ & 0.498 & 0.481 \\
\hline & & No (103) & Yes (57) & Total (160) & & \\
\hline \multirow[t]{4}{*}{ CD4 $>200$ cells $/ \mu \mathrm{L}$} & $\mathrm{CC}$ & $18(17.5 \%)$ & $6(10.5 \%)$ & $24(15.0 \%)$ & 1.390 & 0.238 \\
\hline & TC & $79(76.7 \%)$ & $46(80.7 \%)$ & $125(78.1 \%)$ & 0.344 & 0.558 \\
\hline & TT & $6(5.8 \%)$ & $5(8.8 \%)$ & $11(6.9 \%)$ & 0.498 & 0.481 \\
\hline & & No (141) & Yes (19) & Total (160) & & \\
\hline \multirow[t]{4}{*}{$\mathrm{CD} 4>500$ cells $/ \mathrm{mL}$} & $\mathrm{CC}$ & $21(14.9 \%)$ & $3(15.8 \%)$ & $24(15.0 \%)$ & 0.011 & 0.918 \\
\hline & $\mathrm{TC}$ & $110(78.0 \%)$ & $15(78.9 \%)$ & $125(78.1 \%)$ & 0.009 & 0.926 \\
\hline & TT & $10(7.1 \%)$ & $1(5.3 \%)$ & $11(6.9 \%)$ & 0.087 & 0.767 \\
\hline & & No (27) & Yes (12) & Total (39) & & \\
\hline \multirow[t]{3}{*}{ High viral load } & $\mathrm{CC}$ & $4(14.8 \%)$ & $2(16.7 \%)$ & $6(15.4 \%)$ & 0.022 & 0.882 \\
\hline & TC & $20(74.1 \%)$ & $10(83.3 \%)$ & $30(76.9 \%)$ & 0.401 & 0.526 \\
\hline & TT & $3(11.1 \%)$ & $0(0 \%)$ & $3(7.7 \%)$ & 1.444 & 0.229 \\
\hline
\end{tabular}

$\mathrm{P}$ is significant at $\mathrm{P}<0.05$.

\section{DISCUSSION}

Inflammation is a defense reaction caused by infection or tissue damage (Stadtmann and Zarbock, 2012). Inflammatory processes eliminate the inflammatory stimulus and protect the surrounding tissue from further damage, making it possible for the host to survive. A defect in this system can severely affect the integrity of the organism, which may lead to fatality. This is demonstrated in patients with HIV and AIDS. The reduction of neutrophil recruitment in disease models stimulated by bacteria often results in decreased bacterial clearance and reduced survival (Craig et al., 2009). This also occurs in patients suffering from leukocyte adhesion deficiency, a disease characterized by a defect in leukocyte extravasation. This results in an inappropriate inflammatory response to injury or infection (Etzioni, 2010). Patients with this disease suffer from recurrent bacterial infections and have reduced life expectancy (Etzioni, 2010). Therefore, predisposition to infection exists in different individuals and may affect how they respond to infection. In the present study, we examined the distribution of CXCR2 genotypes in an African population to identify the potential association between the occurrences of opportunistic infections among these patients.

Expression of cytokines and their receptors have been shown to vary in individuals according to single nucleotide polymorphisms, thereby affecting the response to infection. CXCR2 and its chemokine ligands genotypes are involved in a wide range of acute and chronic inflammatory diseases, including acute respiratory distress syndrome (Kurdowska et al., 2002), rheumatoid arthritis (Erdem et al., 2005; Lally et al., 2005), psoriasis (Reich et al., 2001), inflammatory bowel disease (Banks et al., 2003), chronic obstructive pulmonary disease and asthma (Keatings et al., 1996; Beeh et al., 2003; Chapman et al., 2009), aggressive cancer (Snoussi et al., 2010), cystic fibrosis (Koller et al., 1997), and atherosclerosis (Bizzarri et al., 2006). However, whether different genotypes of the genes coding for these cytokines are involved in the susceptibility to opportunistic infections among HIV patients is not clear. 
Recent studies by Gianesin et al. (2012) showed that some variants of the stromal cell-derived factor 1 gene were associated with disease progression among children infected with HIV at birth. Although HIV patients are susceptible to infections because of reduced immune protection, this susceptibility may also depend on the patient's specific genotype, which will affect how quickly or seriously a disease will progress. Salim et al. (2012) demonstrated that the CXCR2 CC genotype in CXCL8 A was more frequent in systemic sclerosis patients compared to controls. However, this genotype has not been examined in HIV-positive patients.

We determined the distribution and associations between the CXCR2 genotypes and opportunistic infections among HIV-infected patients. The CXCR2 TC genotype was found to be more abundant, suggesting that patients in the Limpopo Province primarily carry the heterozygous TC genotype compared to other homozygous genotypes. However, different results obtained by Snoussi et al. (2010) suggested that the CC genotype was the predominant genotype among the Tunisian population. These authors also found a highly significant association between the homozygous CXCR2 $(+1208)$ TT genotype and breast carcinoma in terms of frequency, but also found a significant association with an aggressive phenotype of breast carcinoma as defined by large tumor size, high histological grade, and auxiliary lymph node metastasis (Snoussi et al., 2010). In the present study, we did not determine whether the HIV patients also had carcinomas. However, we found that fewer patients carrying this genotype had chest pain compared to patients carrying other genotypes. Several studies have demonstrated a lack of association between genetic polymorphisms and disease progression in HIV patients or co-infection with other pathogens such as hepatitis C virus (Osinusi et al., 2012). However, the presence of specific genotypes is strongly associated with HIV disease progression. In particular, it has been suggested that genetic variation within the human leukocyte antigen (HLA)-B locus has the strongest impact on HIV disease progression of any polymorphisms within the human genome examined to date (Kløverpris et al., 2012).

In the present study, the TC genotype was more common among patients who did not have loss of appetite, which is a problem faced by most HIV-infected patients, whereas the $\mathrm{CC}$ genotype was more common among patients who suffered from loss of appetite. This suggests that patients who are carriers of the $\mathrm{CC}$ genotype are more likely to suffer from loss of appetite; this results in weight reduction, which is quite common among HIV patients (Atkinson et al., 2012). Similar results have been described previously (Tang et al., 2002). Chest pain may be a manifestation of different infections such as infections by influenza virus or other respiratory viruses, bacterial agents such as the Bacillus tuberculosis, or fungal infections such as Cryptococus neoformans lung infection (Deok-jong et al., 2010). In a study by Hu et al. (2012), diversity at the human Fc $\gamma$ receptors (Fc $\gamma R s$ ) gene was found to be associated with cryptococal meningitis among HIV patients. In the present study, TC genotype carriers showed a significant association with loss of appetite and pain in the chest, suggesting that they may be experiencing chest-related infections such as TB (Alavi et al., 2011), but no association was found between TB and any of the genotypes (CC, TC, and TT). TB is a common opportunistic infection among HIV patients. Previous studies have shown that individuals carrying specific genotypes were more susceptible to TB. For example, a study conducted in Iran showed that the $\mathrm{C}-159 \mathrm{~T}$ polymorphism of the $\mathrm{CD} 14$ gene was associated with TB (AlaviNaini et al., 2012). In contrast, the ATP-binding cassette, sub-family B (encoded by $A B C B-1$ or $M D R-1)$ ABCB-1 C3435T polymorphisms did not affect plasma nevirapine and efavirenz concentrations in HIV/TB co-infected Thai patients or their immunological outcome, but did 
affect virological outcomes in the nevirapine-treated group. This shows that the effect of the host genome on the outcome of infections primarily depends on the particular gene considered. In the present study, we detected no effect of the CXCR2 gene polymorphism on the occurrence of TB among the patients.

The TT genotype was the least represented in our study population and did not appear to be associated with any of the infection/conditions observed among patients. Instead, it appeared to be protective against diarrhea and chest pain. Similar findings have been described previously. In a case-control study involving breast cancer patients with invasive ductal carcinoma, the CXCR $2+1208 \mathrm{C} / \mathrm{T}$ polymorphism showed no differences between studied groups (Kamali-Sarvestani et al., 2007). In a study conducted in Slovakia, the CXCR2 +1208 T allele was the least represented in that community and conferred protection from recurrent acute pyelonephritis (APN), which is the most severe form of urinary tract infection (Javor et al., 2012). Because of the limited number of participants in our study, further studies are necessary to confirm these results. The immunological characteristics of patients showed no association among the genotypes. This suggests that the receptor gene, unlike the cytokine to which it binds, does not affect the immunological characteristics of HIV patients. Previous studies have indicated that specific genotypes may affect the immunological recovery of patients through increased CD4 counts compared to other groups. For example, in a study conducted in Zimbabwe, there was a significant reduction of mortality and attenuation of CD4 cell decrease among patients who were carriers of the IL-10 $-1082 \mathrm{G}$ allele, which has been linked to increased production of IL-10 (Erikstrup et al., 2007).

This is the first study to investigate the effect of CXCR2 T/C polymorphisms among HIV patients in South Africa. We demonstrated that carriers of the TC genotype are more susceptible to chest pain, although this genotype appeared to be protective against loss of appetite; the CC genotype was protective against chest pain, but appeared to increase the susceptibility to headaches. Further studies using larger samples are warranted in order to confirm these results. The CD4 counts as well as the viral load showed no association between genotypes of the CXCR2 gene.

\section{ACKNOWLEDGMENTS}

Research supported by the Research and Publication Committee of the University of Venda and the National Research Foundation (NRF). The authors are very grateful to the management and staff of the Donald Fraser Hospital, the Tshilidzini Hospital, and the Elim Hospital for their co-operation, as well as to the patients who agreed to take part in the study.

\section{REFERENCES}

Alavi-Naini R, Salimi S, Sharifi-Mood B, Davoodikia AA, et al. (2012). Association between the CD14 gene C-159T polymorphism and serum soluble CD14 with pulmonary tuberculosis. Int. J. Tuberc. Lung. Dis. 16: 1383-1387.

Alavi SM, Khosravi AD and Seyedian SS (2011). Mycobacterium tuberculosis infection: A data-based review on tuberculosis in Khuzestan. Res. J. Microbiol. 6: 724-734.

Atkinson E, Miklowski M, Lopez F and Klibert D (2012). A 23-year-old man with fever and malaise. J. La State Med. Soc. 164: 164-8, 170.

Banks C, Bateman A, Payne R, Johnson P, et al. (2003). Chemokine expression in IBD. Mucosal chemokine expression is unselectively increased in both ulcerative colitis and Crohn's disease. J. Pathol. 199: 28-35.

Beeh KM, Kornmann O, Buhl R, Culpitt SV, et al. (2003). Neutrophil chemotactic activity of sputum from patients with 
COPD: role of interleukin 8 and leukotriene B4. Chest 123: 1240-1247.

Bidwell J, Keen L, Gallagher G, Kimberly R, et al. (1999). Cytokine gene polymorphism in human disease: on-line databases. Genes Immun. 1: 3-19.

Bizzarri C, Beccari AR, Bertini R, Cavicchia MR, et al. (2006). ELR+ CXC chemokines and their receptors (CXC chemokine receptor 1 and CXC chemokine receptor 2) as new therapeutic targets. Pharmacol. Ther. 112: 139-149.

Chapman RW, Phillips JE, Hipkin RW, Curran AK, et al. (2009). CXCR2 antagonists for the treatment of pulmonary disease. Pharmacol. Ther. 121: 55-68.

Chiche JD, Siami S, Dhainaut JF and Mira JP (2001). Cytokine polymorphisms and susceptibility to severe infectious diseases. Sepsis 4: 209-215.

Craig A, Mai J, Cai S and Jeyaseelan S (2009). Neutrophil recruitment to the lungs during bacterial pneumonia. Infect. Immun. 77: 568-575.

Deok-jong YS, Worodria W, Davis JL, Cattamanchi A, et al. (2010). The prevalence and clinical course of HIV-associated pulmonary cryptococcosis in Uganda. J. Acquir. Immune. Defic. Syndr. 54: 269-274.

Erdem H, Pay S, Serdar M, Simsek I, et al. (2005). Different ELR (+) angiogenic CXC chemokine profiles in synovial fluid of patients with Behcet's disease, familial Mediterranean fever, rheumatoid arthritis, and osteoarthritis. Rheumatol. Int. 26: 162-167.

Erikstrup C, Kallestrup P, Zinyama-Gutsire RB, Gomo E, et al. (2007). Reduced mortality and CD4 cell loss among carriers of the interleukin-10 -1082G allele in a Zimbabwean cohort of HIV-1-infected adults. AIDS 21: 2283-2291.

Etzioni A (2010). Defects in the leukocyte adhesion cascade. Clin. Rev. Allergy Immunol. 38: 54-60.

Gianesin K, Freguja R, Carmona F, Zanchetta M, et al. (2012). The role of genetic variants of stromal cell-derived factor 1 in pediatric HIV-1 infection and disease progression. PLoS One 7: e44460.

Hu XP, Wu JQ, Zhu LP, Wang X, et al. (2012). Association of Fcy receptor IIB polymorphism with cryptococcal meningitis in HIV-uninfected Chinese patients. PLoS One 7: e42439.

Javor J, Bucova M, Cervenova O, Kralinsky K, et al. (2012). Genetic variations of interleukin-8, CXCR1 and CXCR2 genes and risk of acute pyelonephritis in children. Int. J. Immunogenet. 39: 338-345.

Jiang ZD, Okhuysen PC, Guo DC, He R, et al. (2003). Genetic susceptibility to enteroaggregative Escherichia coli diarrhea: polymorphism in the interleukin-8 promotor region. J. Infect. Dis. 188: 506-511.

Kamali-Sarvestani E, Aliparasti MR and Atefi S (2007). Association of interleukin-8 (IL-8 or CXCL8) -251T/A and CXCR2 +1208C/T gene polymorphisms with breast cancer. Neoplasma 54: 484-489.

Keatings VM, Collins PD, Scott DM and Barnes PJ (1996). Differences in interleukin-8 and tumor necrosis factor-alpha in induced sputum from patients with chronic obstructive pulmonary disease or asthma. Am. J. Respir. Crit. Care Med. 153: 530-534.

Kløverpris HN, Harndahl M, Leslie AJ, Carlson JM, et al. (2012). HIV control through a single nucleotide on the HLA-B locus. J. Virol. 86: 11493-11500.

Koller DY, Nething I, Otto J, Urbanek R, et al. (1997). Cytokine concentrations in sputum from patients with cystic fibrosis and their relation to eosinophil activity. Am. J. Respir. Crit. Care Med. 155: 1050-1054.

Kurdowska A, Noble JM, Grant IS, Robertson CR, et al. (2002). Anti-interleukin-8 autoantibodies in patients at risk for acute respiratory distress syndrome. Crit. Care Med. 30: 2335-2337.

Lally F, Smith E, Filer A, Stone MA, et al. (2005). A novel mechanism of neutrophil recruitment in a coculture model of the rheumatoid synovium. Arthritis Rheum. 52: 3460-3469.

Li W, Albrecht AM and Li M (2012). Inflammation and pancreatic cancer: A tale of two cytokines. J. Cell Biol. 1: 1-2.

Osinusi A, Chary A, Winters MA and Naggie S (2012). IL28B polymorphism is not associated with HCV protease diversity in patients co-infected with HIV and HCV treated with pegylated interferon and ribavirin. J. Med. Virol. 84: 1522-1527.

Otsuka Y, Fujino T, Mori N, Sekiguchi J, et al. (2005). Survey of human immunodeficiency virus (HIV)-seropositive patients with mycobacterial infection in Japan. J. Infect. 51: 364-374.

Reich K, Garbe C, Blaschke V, Maurer C, et al. (2001). Response of psoriasis to interleukin-10 is associated with suppression of cutaneous type 1 inflammation, downregulation of the epidermal interleukin-8/CXCR2 pathway and normalization of keratinocyte maturation. J. Invest. Dermatol. 116: 319-329.

Salim PH, Jobim M, Bredemeier M, Chies JA, et al. (2012). Combined effects of CXCL8 and CXCR2 gene polymorphisms on susceptibility to systemic sclerosis. Cytokine 60: 473-477.

Snoussi K, Mahfoudh W, Bouaouina N, Fekih M, et al. (2010). Combined effects of IL-8 and CXCR2 gene polymorphisms on breast cancer susceptibility and aggressiveness. BMC Cancer 10: 283.

Stadtmann A and Zarbock A (2012). CXCR2: From Bench to Bedside. Front Immunol. 3: 263.

Tang AM, Forrester J, Spiegelman D, Knox TA, et al. (2002). Weight loss and survival in HIV-positive patients in the era of highly active antiretroviral therapy. J. Acquir. Immune. Defic. Syndr. 31: 230-236. 